\title{
Mechanisms underlying resistance to cetuximab in the HNSCC cell line: Role of AKT inhibition in bypassing this resistance
}

\author{
MAGALI REBUCCI ${ }^{1,2,3}$, PAUL PEIXOTO ${ }^{1,3}$, AMÉLIE DEWITTE ${ }^{1,3}$, NICOLE WATTEZ ${ }^{1,2,3}$, \\ MARIE-ADELINE DE NUNCQUES ${ }^{1}$, NICOLAS REZVOY ${ }^{1,2}$, CLAIRE VAUTRAVERS-DEWAS ${ }^{1}$, \\ MARIE-PIERRE BUISINE ${ }^{1,4,5}$, ERIC GUERIN ${ }^{6,7}$, JEAN-PHILIPPE PEYRAT ${ }^{2}$, \\ ERIC LARTIGAU ${ }^{2,4}$ and AMÉLIE LANSIAUX ${ }^{1,2,3,4}$ \\ ${ }^{1}$ Jean-Pierre Aubert Research Center (JPARC) INSERM U837, 59045 Lille; ${ }^{2}$ Centre Oscar Lambret, 59020 Lille; \\ ${ }^{3}$ Institut pour la Recherche sur le Cancer de Lille (IRCL), 59045 Lille; ${ }^{4}$ Université Lille Nord de France, \\ Faculté de Médecine, 59045 Lille; ${ }^{5}$ CHRU de Lille, 59037 Lille; ${ }^{6}$ Université de Strasbourg (UdS), \\ EA4438 Physiopathologie et Médecine Translationnelle, Bâtiment INSERM U682, 67200 Strasbourg; \\ ${ }^{7}$ Laboratoire de Biochimie et Biologie Moléculaire, Hôpitaux Universitaires de Strasbourg, \\ Hôpital de Hautepierre, 67098 Strasbourg Cedex, France
}

Received July 27, 2010; Accepted September 6, 2010

DOI: 10.3892/ijo_00000838

\begin{abstract}
EGFR is frequently overexpressed in head and neck squamous cell cancer (HNSCC). Cetuximab is a monoclonal antibody designed to interact with EGFR, block its activation, reduce the downstream signaling pathways and induce EGFR internalization. This study aims to investigate the role of the EGFR signaling pathway and EGFR internalization in a cetuximab-resistant cell line and to propose a new therapeutic strategy to optimize treatment of HNSCC. The HNSCC cell line, CAL33 was sensitive to gefitinib but resistant to cetuximab. Cetuximab induces an unexpected EGFR phosphorylation in CAL33 cells similarly to EGF but this EGFR activation does not trigger EGFR internalization/degradation, the process currently implicated in the response to cetuximab. Cetuximab inhibits ERK and AKT phosphorylation in cetuximab-sensitive A431 cells, whereas the level of AKT phosphorylation is unmodified in cetuximab-resistant cells. Interestingly, CAL33 cells harbor a PIK3CA mutation. The treatment of CAL33 cells with PI3K inhibitor and cetuximab restores the inhibition of AKT phosphorylation and induces growth inhibition. Our results indicate that EGFR internalization is impaired by cetuximab treatment in CAL33 cells and that the AKT pathway is a central element in cetuximab resistance. The combination of cetuximab with a PI3K inhibitor could be a good therapeutic option in PIK3CA-mutated HNSCC.
\end{abstract}

Correspondence to: Dr Amélie Lansiaux, Laboratoire de Pharmacologie Antitumorale, INSERM U837, Centre Oscar Lambret, 1 Place de Verdun, F-59045 Lille, France

E-mail: a-lansiaux@o-lambret.fr

Key words: AKT pathway, cetuximab, epidermal growth factor receptor, EGFR internalization gefitinib, phosphatidylinositol 3kinase inhibitor

\section{Introduction}

The epidermal growth factor receptor (EGFR) is a member of the ErbB family of tyrosine kinase receptors (1). This receptor, which is implicated in carcinogenesis, is overexpressed in $90 \%$ of head and neck squamous cell cancer (HNSCC), correlating with poor prognosis $(2,3)$. The binding of ligand (i.e., EGF, TGF $\alpha$ ) to EGFR induces the receptor dimerization and autophosphorylation of the intracellular tyrosine kinase domain. EGFR phosphorylation mediates the activation of intracellular signaling pathways such as Ras/Raf/MAPK (mitogen-activated protein kinase) and PI3K/AKT (phosphatidylinositol 3-kinase), which regulate cell proliferation and cell survival respectively $(4,5)$. EGFR is therefore a therapeutic target for cancer treatment (6) and two strategies have been developed to inhibit the EGFR signaling pathway: tyrosine kinase inhibitors (TKIs) and monoclonal antibodies (mAbs) (7). TKI such as gefitinib (Iressa ${ }^{\circledR}$, ZD1839) targets the intracellular tyrosine kinase domain of EGFR, inhibiting autophosphorylation of the receptor and activation. Among anti-EGFR monoclonal antibodies, cetuximab $\left(\right.$ Erbitux $\left.^{\circledR}\right)$ is a chimeric mAb which targets the extracellular domain, blocks ligand binding and thus prevents EGFR activation. Cetuximab inhibits cell proliferation primarily by cell cycle control $(8,9)$ but also modifications of EGFR internalization and degradation (10). Cetuximab is approved in combination with chemotherapy or ionizing radiations in the treatment of metastatic colorectal cancer $(\mathrm{mCRC})$ and $\operatorname{HNSCC}(11,12)$. Despite the overexpression of EGFR in HNSCC and its important role in HNSCC pathogenesis, EGFR inhibitors (gefitinib, cetuximab) have had limited success in monotherapy $(13,14)$. Many patients are refractory to anti-EGFR treatment, showing that EGFR expression is not the only determining factor in response to treatment. Primary resistance could occur in patients who do not achieve stable disease or who progress within months after an initial clinical response, whereas acquired resistance could occur after prolonged treatment (15). Mechanisms that 
mediate resistance to anti-EGFR therapies include autocrine and paracrine production of ligands, secondary mutations, a constitutive activation of downstream pathways, and an activation of alternative pathways such as angiogenesis (16-18). To date, most studies evaluating acquired resistance mechanisms to anti-EGFR have been particularly focused on tyrosine kinase inhibitor treatment in lung cancers and tumoral EGFR mutational status (18). However, it has been widely confirmed that some tumors with wild-type EGFR status also derive significant clinical benefit from anti-EGFR agents, especially in HNSCC, but there have been few investigations in this field. The mechanisms implicated in cetuximab resistance could also be due to the expression of an alternative downstream signaling pathway and/or alterations in EGFR internalization/degradation. It has been demonstrated that endocytic trafficking of EGFR is important in EGFR signaling pathways $(19,20)$ and that internalized EGFR is able to interact with signaling proteins which allow full activation of ERK and PI3K/AKT pathways $(21,22)$. In NSCLC cell lines, the efficiency of cetuximab has been shown to depend on the inhibition of EGFR downstream signaling mediated by ERK and AKT, rather than the inhibition of EGFR itself (19). Scarce data are currently available on the EGFR downstream signaling pathway and EGFR internalization/degradation implicated in resistance to cetuximab in HNSCC.

Our study aims to investigate the role of these mechanisms in a cetuximab-resistant cell line and to propose a new therapeutic strategy to optimize treatment of HNSCC. Our results show that the inhibition of PI3K/AKT pathway restores sensitivity to cetuximab in HNSCC.

\section{Materials and methods}

Cell lines. CAL33, an epidermoid head and neck squamous cell carcinoma cell line derived from an oral squamous cell carcinoma (23), was kindly provided by Dr J.L. Fischel (Centre Antoine Lacassagne, Nice, France). SQ20B, an epidermoid HNSCC cell line, was kindly provided by Professor E. Deutsch (Institut Gustave Roussy, Villejuif, France) and A431, a squamous epidermoid carcinoma cell line, was obtained from ATCC. Cell lines were maintained as monolayer culture in a humidified incubator at $37^{\circ} \mathrm{C}$ and $5 \% \mathrm{CO}_{2}$ in Dulbecco's modified Eagle's medium (DMEM) supplemented with $10 \%$ fetal calf serum (FCS), $1000 \mathrm{U} / \mathrm{ml}$ penicillin and $100 \mu \mathrm{g} / \mathrm{ml}$ streptomycin. In the case of CAL33, $2 \mathrm{mM}$ glutamine was added. All the products for cell culture were from Invitrogen (Cergy-Pontoise, France).

Compounds. Cetuximab monoclonal antibody (Erbitux ${ }^{\circledR}$ ) was provided by Merck KgaA (Germany) at $2 \mathrm{mg} / \mathrm{ml}$ solution, stored at $4^{\circ} \mathrm{C}$, and EGFR tyrosine kinase inhibitor gefitinib (ZD1839; Iressa ${ }^{\circledR}$ ) was obtained from Institut de Chimie Pharmaceutique Albert Lespagnol (France). Gefitinib was stored in a $10 \mathrm{mM}$ stock solution in pure dimethylsulfoxide (DMSO) and dilutions were made daily in growth medium. EGF (epidermal growth factor) human recombinant was purchased from Sigma Aldrich (France) and stored at $50 \mu \mathrm{g} / \mathrm{ml}$ in $10 \mathrm{mM}$ acetic acid containing $0.1 \%$ BSA (bovine serum albumin). PI3K inhibitor, LY294002, was purchased from Calbiochem (Merck, France) and stored in a $50 \mathrm{mM}$ stock solution in DMSO. In experiments, the final concentration of DMSO and acetic acid were low enough not to alter cell growth.

DNA extraction and mutation analysis of EGFR, KRAS, $B R A F$ and PIK3CA. Total genomic DNA was extracted from cell lines using QIAamp DNA mini kit (Qiagen, France) according to the manufacturer's instructions. Exons 18 through 21 of EGFR, exon 2 of KRAS and exon 15 of BRAF were PCR amplified using the HotStarTaq Master Mix kit (Qiagen) following the manufacturer's instructions. Primer sequences are available on request. PCR products for EGFR exons 18-21 were purified and submitted to direct sequencing using BigDye $^{\text {TM }}$ Terminator version 3.1 and analyzed with a 3130XL automated sequencer (Applied Biosystems, France). KRAS codons 12 and 13 and BRAF codon 600 were analysed by pyrosequencing. PCR products were purified and submitted to pyrosequencing on the PyroMark ${ }^{\mathrm{TM}} \mathrm{MD}$ system (Biotage, Qiagen) according to the specifications of the manufacturer.

Exons 1, 2, 9 and 20 of PIK3CA gene were amplified using the following intron-exon junction PCR primers (forward and reverse, respectively): exon 1 (5'-CTG CTT TGG GAC AAC CAT AC-3' and 5'-CCA ATT TCT CGA TTG AGG ATC-3'), exon 2 (5'-CTA CAG AGT TCC CTG TTT GC-3' and 5'-GAC ACA GGT AGA AGA CTG CAC-3'), exon 9 (5'-CAG AGT AAC AGA CTA GCT AG-3' and 5'-GCT GAG ATC AGC CAA ATT CAG-3') and exon 20 (5'-GCT TGG CTC TGG AAT GCC AG-3' and 5'-GTG TGG AAT CCA GAG TGA GC-3'). All PCRs were carried out in a final volume of $50 \mu 1$ containing $50 \mathrm{ng}$ of genomic DNA using AmpliTaq Gold DNA polymerase (Applied Biosystems). Touchdown thermocycling conditions were as follows: $94^{\circ} \mathrm{C}(10 \mathrm{~min})$ for 1 cycle, $94^{\circ} \mathrm{C}(1 \mathrm{~min}), 64-58^{\circ} \mathrm{C}(30-50 \mathrm{sec}$, with annealing temperature decreasing of $2^{\circ} \mathrm{C}$ every 4 cycles $), 72^{\circ} \mathrm{C}(1 \mathrm{~min} 30 \mathrm{sec})$ for 16 cycles, $94^{\circ} \mathrm{C}(1 \mathrm{~min}), 55^{\circ} \mathrm{C}(50 \mathrm{sec}), 72^{\circ} \mathrm{C}(1 \mathrm{~min} 30 \mathrm{sec})$ for 19 additional cycles and a final extension step at $72^{\circ} \mathrm{C}$ for $10 \mathrm{~min}$. PCR products were purified using Amicon Ultra-0.5 Centrifugal Filter Unit with Ultracel-30 membrane (Millipore, France). Both DNA strands were sequenced using forward and reverse amplification primers as sequencing primers and BigDye Terminator V1.1 Cycle Sequencing Kit reagents according to manufacturer's instructions (Applied Biosystems). EDTA-ethanol purified sequencing fragments were separated by capillary electrophoresis and detected via laser-induced fluorescence on an ABI PRISM 3130xl Genetic Analyzer (Applied Biosystems). Exonic sequences were compared with the PIK3CA GenBank reference sequence (accession number NM_006218.2) using SeqScape software V2.5 (Applied Biosystems).

Growth inhibition assay. Growth inhibition was assessed using MTS assay with CellTiter 96 Aqueous One Solution Cell Proliferation Assay Kit (Promega, France). Cells (1,5003,000 cells) were seeded into a 96-well plate. Twenty-four hours later, cetuximab, gefitinib or LY294002 were added in varying concentrations and incubated for $72 \mathrm{~h}$ at $37^{\circ} \mathrm{C}$. CellTiter 96 Aqueous One Solution $(20 \mu \mathrm{l})$ was then added to each well and the plate was incubated for a further 1-2 $\mathrm{h}$ at $37^{\circ} \mathrm{C}$. Absorbance was measured at $492 \mathrm{~nm}$ with a $96-$ well plate reader. Three independent experiments were performed 
Table I. Technical conditions of Western blot analysis: the primary antibodies.

\begin{tabular}{lcccc}
\hline Antibody & MW (kDa) & Source & Dilution & Supplier \\
\hline P-EGFR Tyr1173 & 175 & Rabbit & $1 / 1000$ TBST 1\% milk & Santa Cruz \\
P-EGFR Tyr1045 & 175 & Rabbit & $1 / 1000$ TBST 1\% BSA & Cell Signaling \\
P-EGFR Tyr1068 & 175 & Rabbit & $1 / 1000$ TBST 1\% BSA & Cell Signaling \\
EGFR & 170 & Rabbit & $1 / 1000$ TBST 1\% milk & Santa Cruz \\
P-ERK1/2 Thr202/Tyr204 & $42-44$ & Mouse & $1 / 2000$ TBST 1\% milk & Cell Signaling \\
ERK 1/2 & $42-44$ & Rabbit & $1 / 1000$ TBST 1\% milk & Cell Signaling \\
P-AKT Ser473 & 60 & Rabbit & $1 / 2000$ TBST 5\% BSA & Cell Signaling \\
AKT & 60 & Mouse & $1 / 2000$ TBST 5\% milk & Cell Signaling \\
PARP & $116-86$ & Rabbit & $1 / 1000$ TBST 1\% milk & Santa Cruz \\
HSC-70 & 70 & Mouse & $1 / 3000$ TBST 1\% milk & Santa Cruz \\
\hline
\end{tabular}

Cell Signaling Inc. (Ozyme, France), Santa Cruz (TebuBio, France).

in three replicate wells for each drug concentration. The $\mathrm{IC}_{50}$ (inhibition concentration 50) value was defined as the concentration needed for $50 \%$ reduction in absorbance calculated from the survival curves by ShortCut for SoftMax Pro software.

Cell cycle analysis. Cells $\left(2.5-4 \times 10^{5}\right)$ were seeded into a 6 -well plate for $24 \mathrm{~h}$ incubation and then treated with $30 \mathrm{nM}$ cetuximab, $5 \mu \mathrm{M}$ gefitinib or $10 \mu \mathrm{M}$ LY294002 for $72 \mathrm{~h}$. Supernatants and cells were collected and fixed with cold $70 \%$ ethanol for $24 \mathrm{~h}$. The cells were then stained with propidium iodide (50 $\mu \mathrm{g} / \mathrm{ml}$, Interchim, France) and RNase solution $(100 \mu \mathrm{g} / \mathrm{ml}$, Sigma Aldrich) in PBS for $30 \mathrm{~min}$ in the dark at room temperature. Cell cycle distribution was determined on a Becton-Dickinson FACScan flow cytometer using the Cell QuestPro software and analyzed by WinMDI software.

Western blot analysis. Cells were grown in $100 \mathrm{~mm}$ dishes until subconfluence and then exposed to different treatments. After removal media, the cells were washed once with icecold PBS and scraped into $300 \mu 1$ ice-cold lysis buffer [50 mM Tris- $\mathrm{HCl}, \mathrm{pH} 7.9,120 \mathrm{mM} \mathrm{NaCl}, 1 \%$ Nonidet P40, $1 \mathrm{mM}$ EDTA, $5 \mathrm{mM} \mathrm{NaF}, 1 \mathrm{mM} \mathrm{Na} \mathrm{VO}_{4}, 0.04 \mathrm{mM}$ AEBSF and a commercial protease inhibitor mixture (Roche Applied Science, France)] and incubated for $2 \mathrm{~h}$ at $4^{\circ} \mathrm{C}$. Thereafter, insoluble debris was pelleted by centrifugation at $12,000 \mathrm{~g}$ for $30 \mathrm{~min}$ at $4^{\circ} \mathrm{C}$, supernatants were collected and the protein concentration was determined by Lowry assay (DC Protein assay, Bio-Rad, France). Lysate samples containing equal amounts of protein were then added to SDS-PAGE loading buffer (100 mM Tris- $\mathrm{HCl}, \mathrm{pH} 6.8,200 \mathrm{mM}$ DTT, 4\% SDS, $0.2 \%$ bromophenol blue and $20 \%$ glycerol) and heated for $3 \mathrm{~min}$ at $90^{\circ} \mathrm{C}$. Proteins $(30 \mu \mathrm{g})$ were resolved on a reducing $10 \%$ SDS polyacrylamide gel and transferred onto a nitrocellulose membrane (GE Healthcare, France). After gel transfer, the membrane was incubated with blocking solution for $1 \mathrm{~h}$ and then probed with the primary antibody (Table I). The membrane was washed three times with TBS- $0.2 \%$ Tween for $5 \mathrm{~min}$ and finally hybridized with the HRP-conjugated donkey anti-rabbit IgG or HRP-conjugated sheep anti-mouse (GE Healthcare) for $1 \mathrm{~h}$ at room temperature followed by three washes with TBS- $0.2 \%$ Tween. Bands were detected by autoradiography on X-ray film using the enhanced chemiluminescence (ECL) detection system (GE Healthcare).

Flow cytometry analysis. The cells were incubated with $30 \mathrm{nM}$ cetuximab or EGF $(50 \mathrm{ng} / \mathrm{ml})$ for $30 \mathrm{~min}-6-24 \mathrm{~h}$ at $37^{\circ} \mathrm{C}$. Cells were isolated by exposure to trypsin, and $5 \times 10^{5}$ cells were incubated for $1 \mathrm{~h}$ at $4^{\circ} \mathrm{C}$ either with phycoerythrin (PE)-conjugated mouse mAb to EGFR (dilution 1/5, BD Pharmingen, France) or with a PE-conjugated isotypematched control mAb (dilution 1/5) in $100 \mu \mathrm{l}$ PBS. The cells were washed twice with PBS and then analyzed by flow cytometry (FACScalibur, Becton-Dickinson) to detect the intensity of EGFR staining at the cell surface.

Immunofluorescence analysis. Cells $\left(8 \times 10^{5}\right)$ were seeded in 8-well Lab-Tec Chamber Slides (Nunc) and fixed with methanol for $10 \mathrm{~min}$ at $-20^{\circ} \mathrm{C}$, permeabilized with $0.2 \%$ Triton X-100 for $10 \mathrm{~min}$ at room temperature, washed three times with PBS and exposed to $3 \%$ BSA for $1 \mathrm{~h}$ at room temperature. The cells were incubated with EGFR antibody for $1 \mathrm{~h}$ at room temperature. The cells were washed three times with PBS and then incubated for $1 \mathrm{~h}$ with Alexa 488labeled goat antibody to rabbit IgG (dilution 1/1600, Molecular Probe). The chamber slides were mounted in fluorescence mounting medium Vectashield with DAPI (Vector Laboratories) and fluorescence signals were visualized with a fluorescence microscope (Leica) with X63 oil objective.

\section{Results}

EGFR expression and EGFR, KRAS and BRAF status of $H N S C C$ and A431 cell lines. In order to explore the effects of EGFR inhibitors, gefitinib and cetuximab, we measured EGFR expression by flow cytometry using two epidermoid head and neck cancer cell lines (CAL33, SQ20B) and one human epidermoid cancer cell line (A431) described as overexpressing EGFR $(24,25)$. The flow cytometric analysis 
Table II. EGFR expression and EGFR, KRAS, BRAF status of HNSCC and A431 cell lines. a

\begin{tabular}{lccccc}
\hline Cell line & Type & $\begin{array}{c}\text { EGFR expression } \\
\text { MFI }( \pm \text { SD })\end{array}$ & $\begin{array}{c}\text { EGFR status } \\
(\text { exons 18-21) }\end{array}$ & $\begin{array}{c}\text { KRAS status } \\
(\text { codons 12-13) }\end{array}$ & $\begin{array}{c}\text { BRAF status } \\
\text { (codon 600) }\end{array}$ \\
\hline A431 & Epidermoid & $362(19)$ & Wild-type & Wild-type & Wild-type \\
CAL33 & HNSCC & $84(4)$ & Wild-type & Wild-type & Wild-type \\
SQ20B & HNSCC & $223(11)$ & Wild-type & Wild-type & Wild-type \\
\hline
\end{tabular}

aThe MFIs (median fluorescence intensity) were standardized for comparison using the following formula: [(MFI-EGFR) - (MFI-isotype control)/(MFI-isotype control)]. MFI represents the mean of three independent experiments $(n=3)$ with standard deviation (SD). Sequencing methods are detailed in Materials and methods. EGFR, epidermal growth factor receptor; HNSCC, head and neck squamous cell cancer.

showed that all cells of these three cell lines overexpressed EGFR at various levels on the cell surface (Table II). The three cell lines harbored wild-type EGFR status on exons 18-21. Moreover, cell lines presented wild-type KRAS and $B R A F$ status.

Differential effects of gefitinib or cetuximab in HNSCC and A431 cell lines. To compare the two different EGFR inhibition strategies, we used cetuximab and gefitinib. Cell growth was measured by MTS assay. After gefitinib treatment, CAL33, SQ20B and A431 cells showed a relevant maximal growth inhibition which is comparable in the three cell lines [55\%, $47.8 \%$ and $45 \%$ respectively (Fig. 1A)]. In accordance with these results, the efficient dose of $5 \mu \mathrm{M}$ gefitinib was used in subsequent experiments. The cetuximab effect was not comparable in any of the cell lines. In A431 cells, we found $40 \%$ maximal growth inhibition in response to cetuximab. In contrast, the growth inhibition in both HNSCC cells was minor with maximum growth inhibition of $16.8 \%$ and $6.2 \%$ for CAL33 and SQ20B respectively after $72 \mathrm{~h}$ of incubation, and increasing concentration of cetuximab until $240 \mathrm{nM}$ had no effect on growth inhibition. Accordingly, the efficient dose of $30 \mathrm{nM}$ cetuximab was used in subsequent experiments. To explore the different effects of these EGFR inhibitors on cell growth, we conducted a cell cycle analysis by flow cytometry (Fig. 1B). Cells were treated with $30 \mathrm{nM}$ cetuximab or $5 \mu \mathrm{M}$ gefitinib for $72 \mathrm{~h}$. Flow cytometric analysis after gefitinib treatment revealed an increase in the $\mathrm{G}_{0} / \mathrm{G}_{1}$ phase and a strong decrease in the $\mathrm{S}$ phase for three cell lines. No increase in the sub- $\mathrm{G}_{1}$ phase corresponding to an apoptotic process was observed after gefitinib treatment in any cell line. In the HNSCC cell lines, cetuximab treatment induced a slight accumulation of cells in the $G_{0} / G_{1}$ phase compared to the control (63.3-68.2\% for CAL33 and 44.8$48.1 \%$ for SQ20B) and a slight decrease in the S phase (13.8$10 \%$ for CAL33 and 9.3-6.5\% for SQ20B). In contrast, cetuximab strongly increased the $\mathrm{G}_{0} / \mathrm{G}_{1}$ population in $A 431$ cells compared to the control (52.9-79.8\%) and decreased the $\mathrm{S}$ population $(27.2-8.7 \%)$. We observed an increase in the sub- $\mathrm{G}_{1}$ population $(0.8-3.1 \%)$ only in A431 cells in response to cetuximab. To confirm the implication of an apoptotic process in A431 cells, we studied PARP cleavage by Western blot analysis after treatment with $30 \mathrm{nM}$ cetuximab or $5 \mu \mathrm{M}$ gefitinib for $72 \mathrm{~h}$ (Fig. 1C). According to previous cell cycle results, PARP cleavage was detected in A431 cells whereas cetuximab had no apoptotic effect in CAL33 and SQ20B. No PARP cleavage was observed in response to gefitinib treatment in all three cell lines in agreement with the absence of sub- $\mathrm{G}_{1}$ population in cell cycle analysis.

These results show that HNSCC cell lines present different sensitivity to cetuximab and gefitinib treatment in contrast to the A431 cell line, which is sensitive to both anti-EGFR agents. These data suggest that EGFR expression does not correlate with sensitivity to anti-EGFR agents. Therefore, we chose CAL33 and A431 as cetuximab-resistant and -sensitive cells respectively, for the following experiments.

Cetuximab induces EGFR phosphorylation but fails to trigger the activation of ERK and AKT pathways in cetuximabresistant cell line. To explore the molecular mechanisms underlying the difference in cellular response to cetuximab and gefitinib treatment, we examined the effects on EGFR, ERK and AKT phosphorylation in cetuximab-resistant and -sensitive cells by Western blot analysis. Cells were incubated for $24 \mathrm{~h}$ with 3-30-300 $\mathrm{nM}$ cetuximab or 1-5-10 $\mu \mathrm{M}$ gefitinib (Fig. 2). Gefitinib, which decreases cell proliferation in A431 cells (Fig. 1A), produced a strong decrease in phosphorylated EGFR on tyrosine 1173, 1045 and 1068. A strong abolition of ERK and AKT phosphorylation was also visualized. In CAL33 cell line, EGFR is not constitutively phosphorylated. However, gefitinib induced a strong decrease in ERK and AKT phosphorylation in relation to growth inhibition. According to the decrease in cell proliferation in both cell lines, gefitinib inhibits the EGFR downstream signaling pathways. Cetuximab decreased cell proliferation in A431 cells but not in HNSCC cells (Fig. 1A). Surprisingly, cetuximab produced no change in EGFR phosphorylation after $24 \mathrm{~h}$ of treatment, but induced a strong decrease in phosphorylated ERK and AKT in cetuximab-sensitive cell line (Fig. 2). Interestingly, ERK phosphorylation declined, but AKT phosphorylation was unmodified (at the expected dose of $30 \mathrm{nM}$ ) in the cetuximab-resistant cell line despite an increase in EGFR phosphorylation on tyrosine 1173 and 1068 after cetuximab treatment. Taken together, these data suggest that sensitivity to anti-EGFR agents is correlated with inhibition of ERK and AKT phosphorylation.

Cetuximab does not induce EGFR internalization/degradation or modify AKT phosphorylation in cetuximab-resistant cell line. To understand the EGFR activation and non-modification 


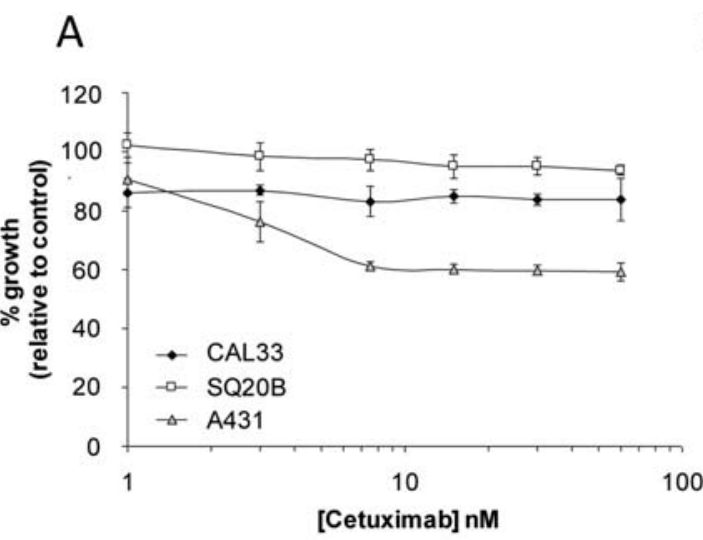

B
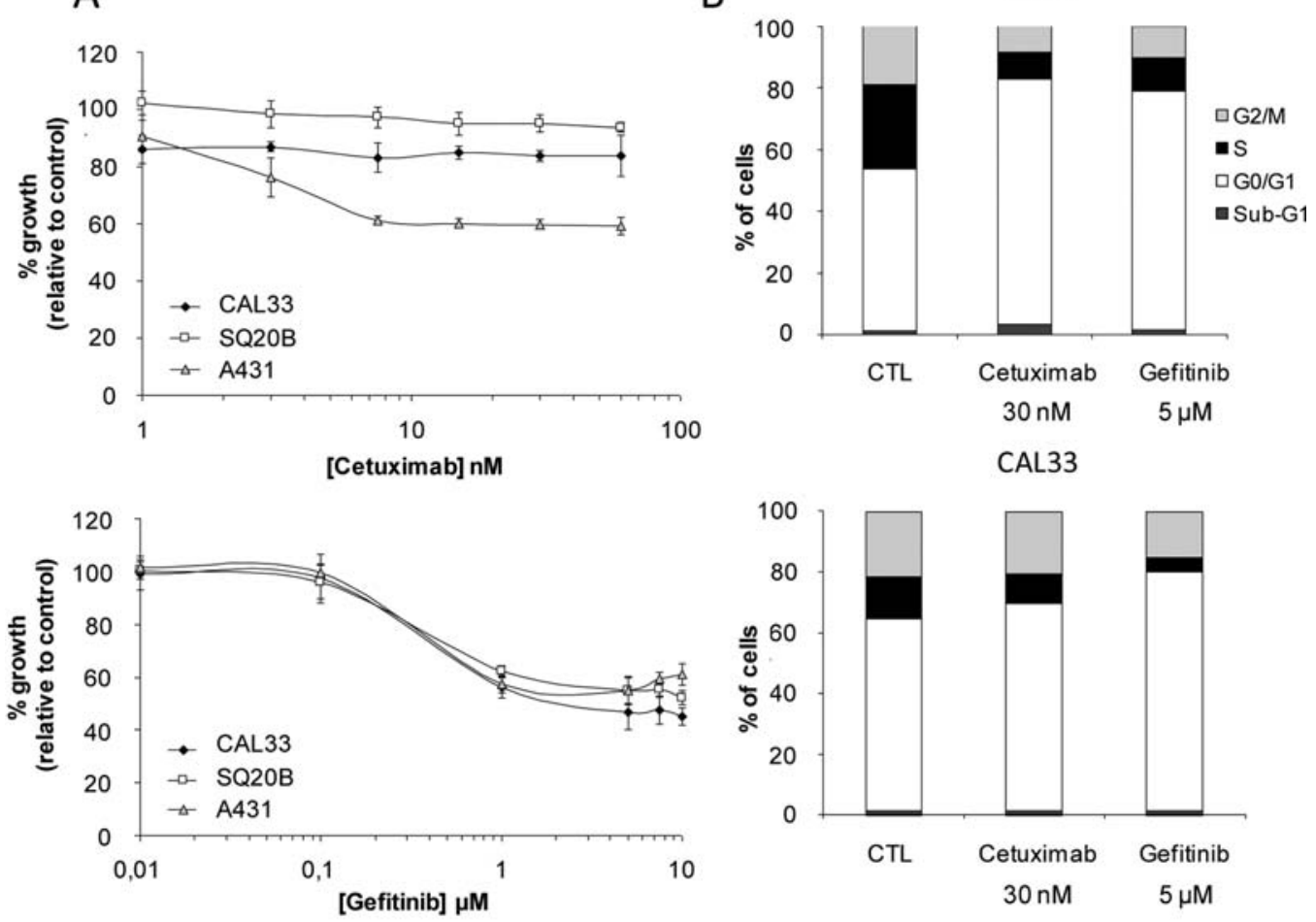

C

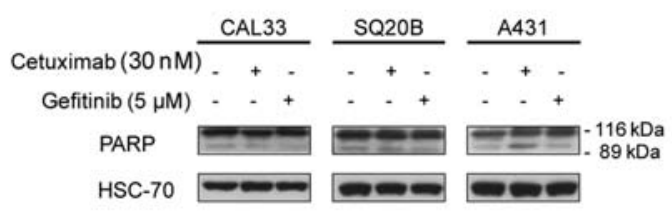

SQ20B

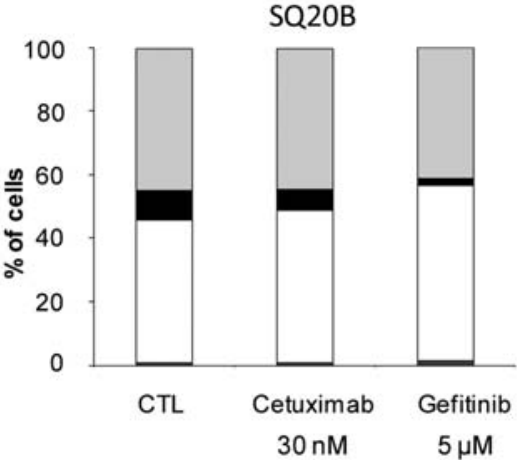

Figure 1. Differential effects of anti-EGFR agents on proliferation (A), cell cycle (B) and PARP cleavage (C) in A431 and HNSCC cell lines. (A), Dose-dependent response curves of CAL33, SQ20B and A431 cell lines to gefitinib and cetuximab treatment. The inhibition of cell proliferation after gefitinib or cetuximab treatment at different concentrations for $72 \mathrm{~h}$ was measured by MTS assay and shown as a percentage of the optical density value of control cells (untreated) for each tested concentration. Data represent the mean of three independent experiments ( $\mathrm{n}=3$ ) performed in triplicate with standard deviation (SD). (B), Effect of cetuximab $(30 \mathrm{nM})$ or gefitinib $(5 \mu \mathrm{M})$ for $72 \mathrm{~h}$ on cell cycle distribution analyzed by flow cytometry. Cell distribution was analyzed by WinMDI software. Data represent the mean of three independent experiments $(n=3)$. (C), PARP cleavage was visualized by the formation of the 89 kDa PARP cleavage fragment by Western blot analysis. After $72 \mathrm{~h}$ of cetuximab $(30 \mathrm{nM})$ or gefitinib $(5 \mu \mathrm{M})$ treatment, proteins were lysated before Western blot analysis.

of AKT phosphorylation in cetuximab-resistant cells by cetuximab, we compared the kinetics of EGFR phosphorylation after EGF or cetuximab treatment in cetuximabresistant vs. sensitive cell lines.

In cetuximab-sensitive cells (A431), EGF stimulation induced a rapid EGFR phosphorylation $(5 \mathrm{~min}$ ) until $8 \mathrm{~h}$ with a decrease in intensity in a time-dependent manner on the three sites of phosphorylation studied (Fig. 3A). Interestingly, we noted that EGFR expression was slightly increased after 5 and $30 \mathrm{~min}$. Treatment with cetuximab induced a strong and rapid decrease in EGFR phosphorylation after 5 min until $8 \mathrm{~h}$. This inhibition disappeared after $24 \mathrm{~h}$. A weak decrease in total EGFR expression was observed at 8 and $24 \mathrm{~h}$. In contrast, EGF stimulation also induced EGFR phosphorylation after 5-30 min in cetuximab-resistant CAL33 cells but we observed a strong, early ( $2 \mathrm{~h})$ and prolonged $(24 \mathrm{~h})$ decrease in EGFR expression corresponding to EGFR degradation
(Fig. 3B). Cetuximab induced slight EGFR phosphorylation on tyrosine 1173 and 1068 (from $5 \mathrm{~min}$ to $24 \mathrm{~h}$ ) and not on tyrosine 1045, which is involved in EGFR internalization/ degradation. Interestingly, cetuximab had no effect on the total EGFR expression contrary to EGF stimulation in this cell line. Western blot analysis showed that EGF and cetuximab treatments induced a slow EGFR turnover (internalization/ degradation) in cetuximab-sensitive cells. In cetuximabresistant cells, despite the induction of EGFR phosphorylation by both treatments, we observed a rapid EGFR turnover induced by EGF, but an absence of EGFR degradation after cetuximab treatment.

To confirm the incapacity of cetuximab to induce EGFR internalization/degradation in cetuximab-resistant cells, we determined EGFR expression by flow cytometry and EGFR localization by immunofluorescence after EGF or cetuximab treatment (Fig. 4). In A431 cells, EGF induced a rightward 


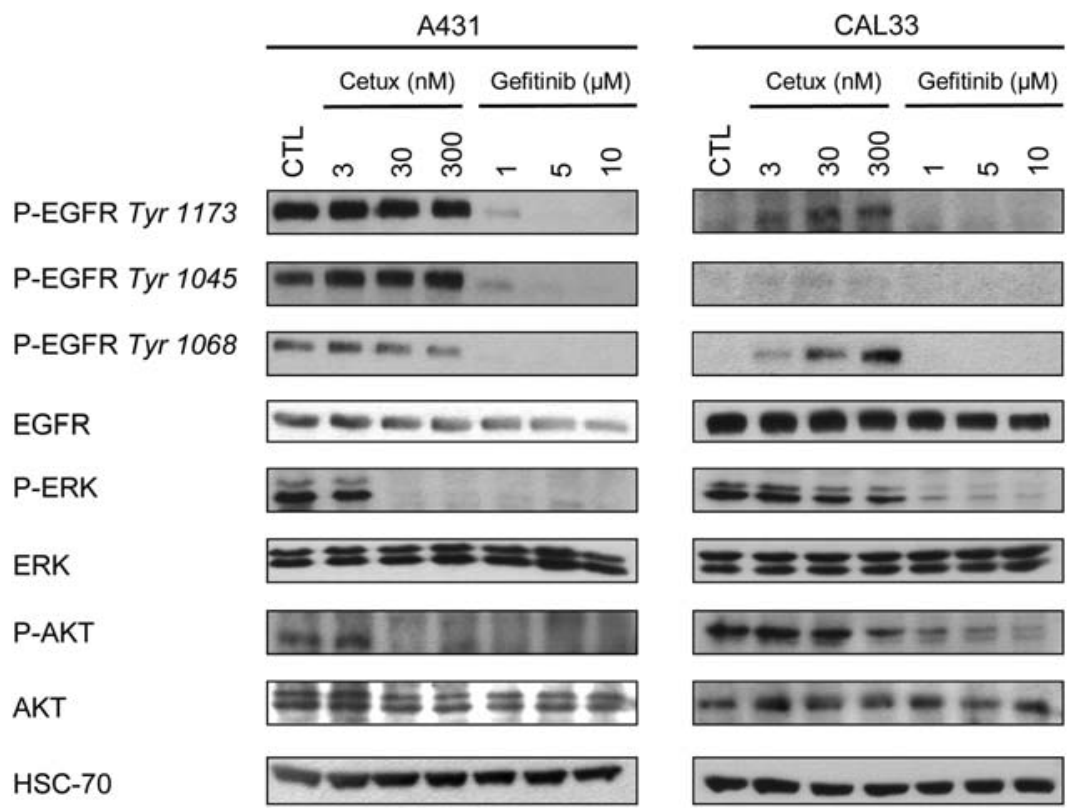

Figure 2. Dose effects of cetuximab (Cetux) or gefitinib treatment on EGFR signaling pathways in A431 and CAL33 cell lines. A431 and CAL33 were treated for $24 \mathrm{~h}$ with 3, 30, $300 \mathrm{nM}$ cetuximab or 1, 5, $10 \mu \mathrm{M}$ gefitinib. Cells lysated were then separated by SDS-PAGE and immunoblotted using the indicated antibodies (Materials and methods). P-EGFR Tyr1173, Tyr1045, Tyr1068 represent phosphorylated EGFR at these different phosphorylation sites. The level of HSC-70 was used as a protein-loading reference control in each cell line.

A

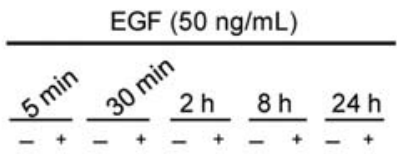

P-EGFR Tyr 1173

P-EGFR Tyr 1045

P-EGFR Tyr 1068

EGFR

P-AKT

AKT

HSC-70
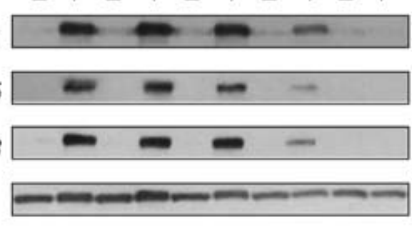

$-\cdots-\cdots-\cdots$

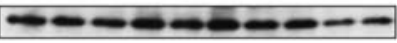

$-----\cdots$

Cetuximab (30 nM)

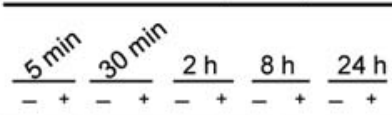

P-EGFR Tyr 1173

P-EGFR Tyr 1045

P-EGFR Tyr 1068 -

EGFR

P-AKT

AKT

HSC-70

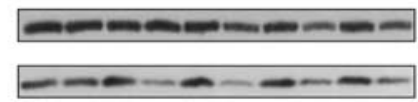

- - - - - - -

$----\infty-\infty-\infty$
B

CAL33

\begin{tabular}{|c|c|}
\hline & EGF $(50 \mathrm{ng} / \mathrm{mL})$ \\
\hline & $5^{\text {nल }} 3^{0 \text { n" }} 2 h \quad 8 h \quad 24 h$ \\
\hline & $-+-+-_{-}+\overline{-}_{+}$ \\
\hline EGFR Tyr 1173 & 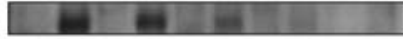 \\
\hline P-EGFR Tyr 1045 & $=2$ \\
\hline P-EGFR Tyr 1068 & $=0$ \\
\hline EGFR & $-------\cdots$ \\
\hline P-AKT & 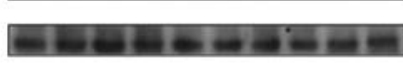 \\
\hline AKT & $-----\cdots$ \\
\hline & \\
\hline
\end{tabular}

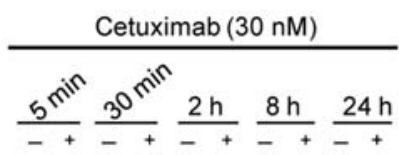

P-EGFR Tyr 1173

P-EGFR Tyr 1045

P-EGFR Tyr 1068

EGFR

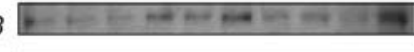

P-AKT

AKT

HSC-70
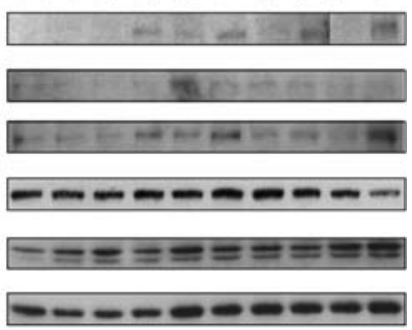

$---\cdots-\cdots$

Figure 3. Kinetic of activation and degradation of EGFR, and effect on AKT activation after EGF or cetuximab treatment in A431 (A) and CAL33 (B) cell lines. Cells were incubated at the indicated times in the presence of EGF (50 ng/ml) or cetuximab $(30 \mathrm{nM})$. Cells were lysed and immunoblotted with indicated antibodies. The level of HSC-70 was used as a protein-loading reference control in each cell line. In A431 blots, exposure time is shorter for EGF treatment than for cetuximab treatment, explaining the absence of EGFR phosphorylation in control cells. 
A
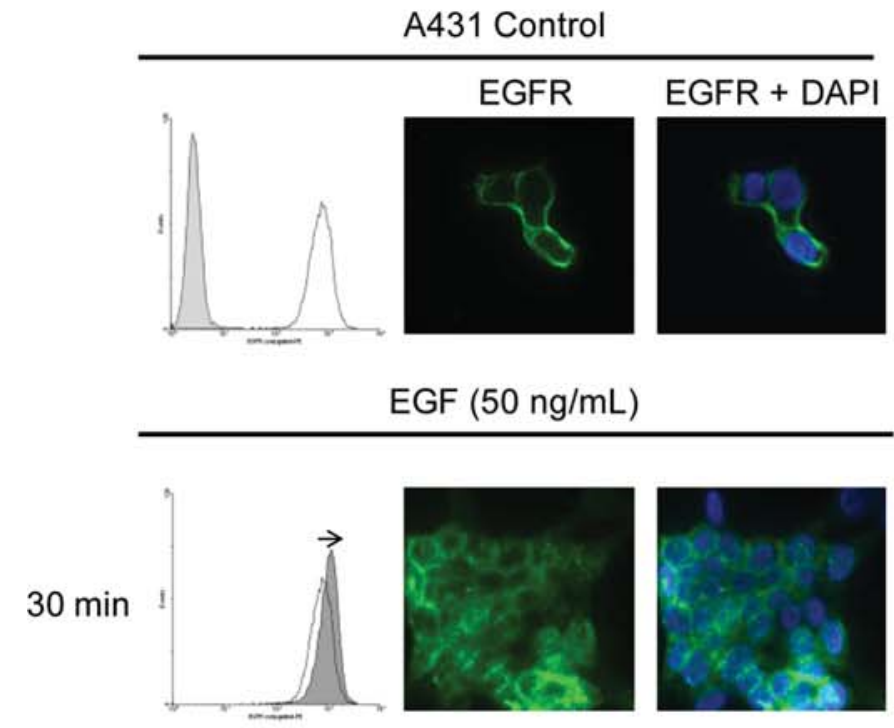

$6 \mathrm{~h}$

$24 \mathrm{~h}$
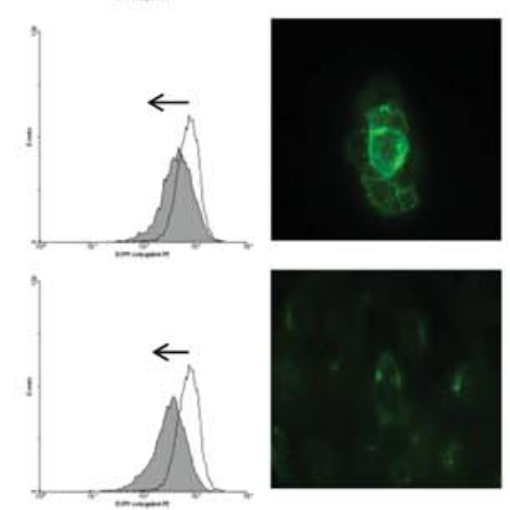

Cetuximab (30 nM)
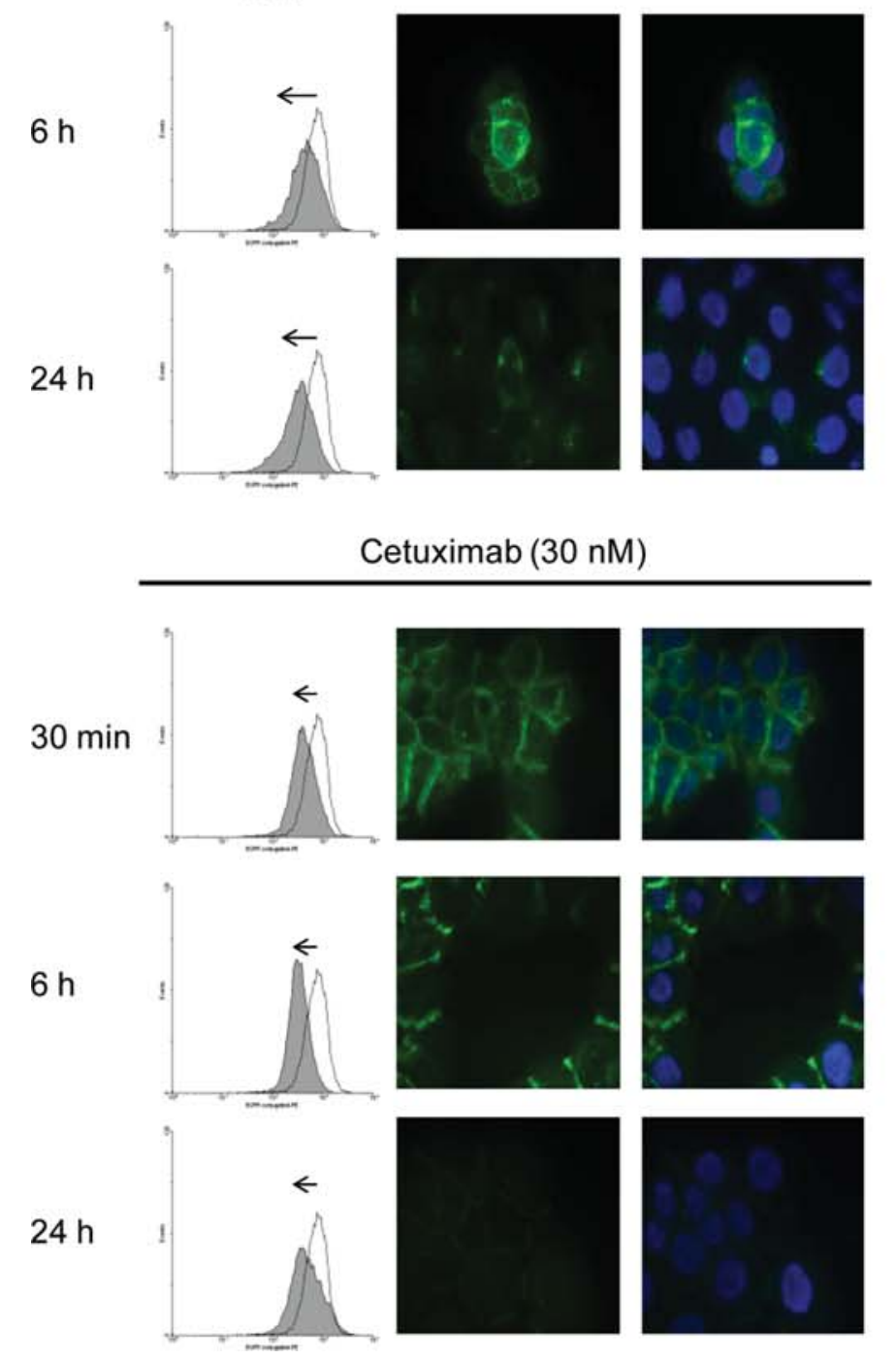

B
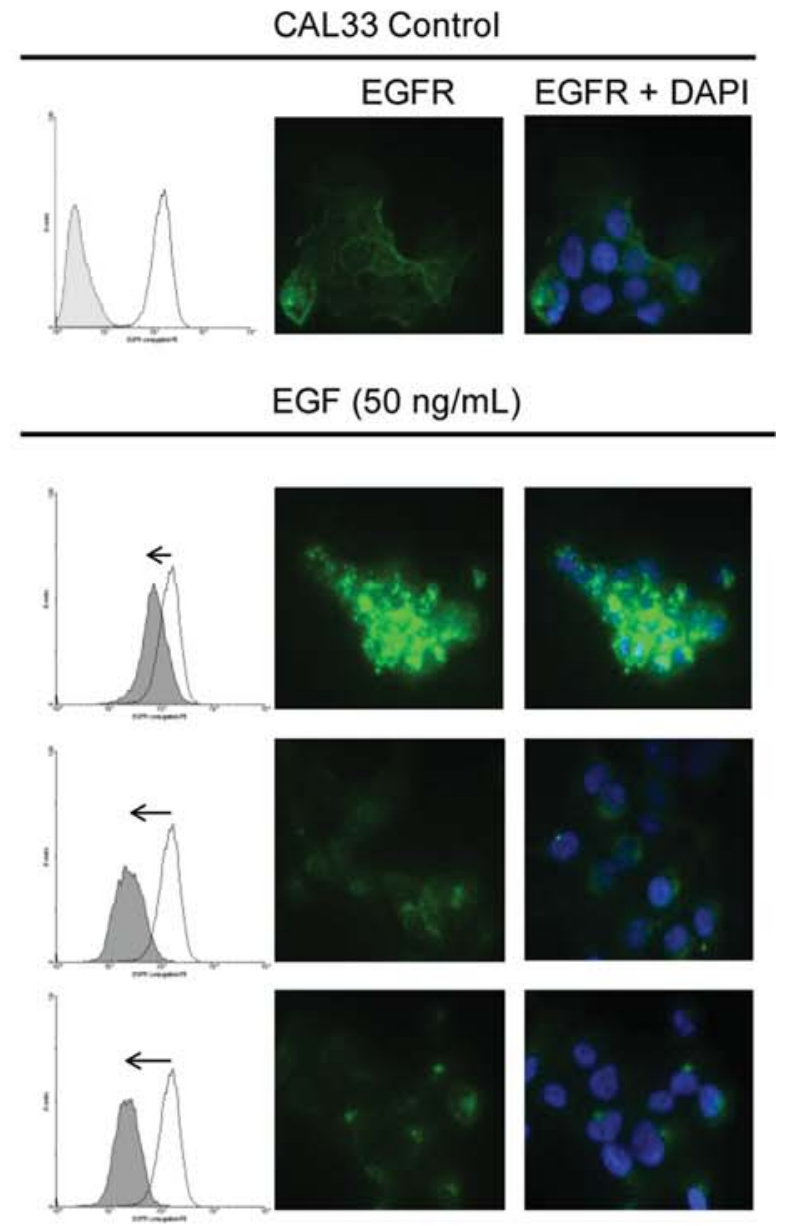

Cetuximab (30 nM)
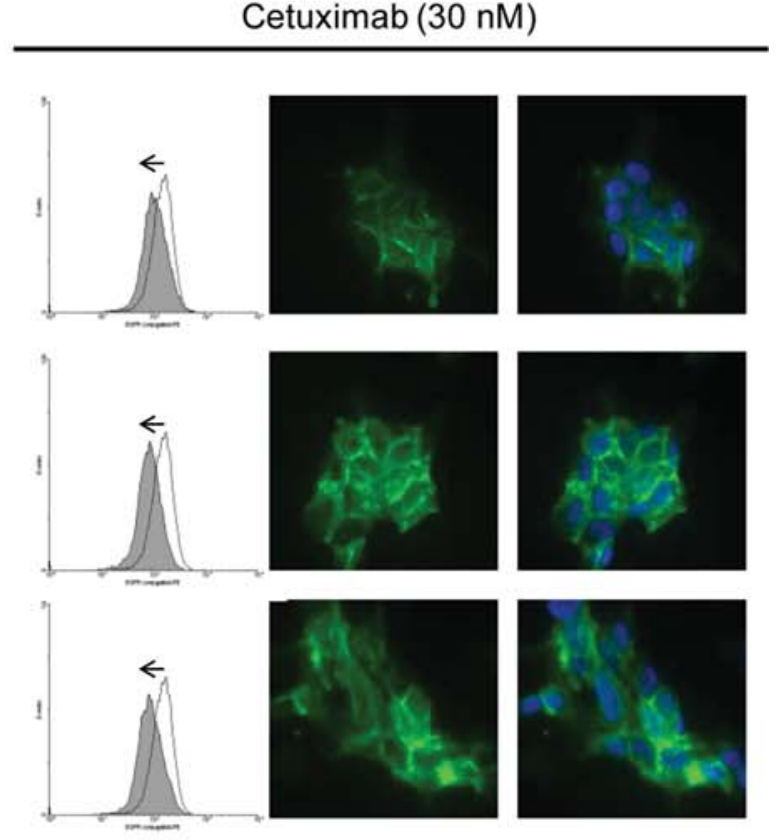

Figure 4. EGFR internalization/degradation and localization after EGF or cetuximab treatment in A431 (A) and CAL33 (B) cell lines. Cells were incubated at the indicated times in the presence of EGF $(50 \mathrm{ng} / \mathrm{ml})$ or cetuximab $(30 \mathrm{nM})$. For flow cytometry, cells were stained with either a PE-conjugated mAb to EGFR or a PE-labeled isotype matched mAb during $1 \mathrm{~h}$ on ice and analyzed by flow cytometry. Representative flow cytometry graphs of relative cell number vs. PE fluorescence are shown. In control graphs, the purple peak represents the isotypic control. The empty peak represents cell surface EGFR without treatment and grey peaks represent EGFR on cell surface after EGF or cetuximab treatment. Arrows show the right or left shift of EGFR expression. Experiments were performed three times $(\mathrm{n}=3)$. For immunofluorescence staining, cells were seeded on a coverslip and treated with EGF (50 ng/ml) or cetuximab (30 $\mathrm{nM})$ at the indicated times. Cells were fixed, permeabilized and stained with EGFR antibody and Alexa 488-labeled secondary antibody (green). Cell nuclei were counterstained with DAPI (blue). Fluorescence signals were visualized with a fluorescence microscope, and the merged images are shown. Pictures were obtained with an objective $\mathrm{x} 63$. 
A

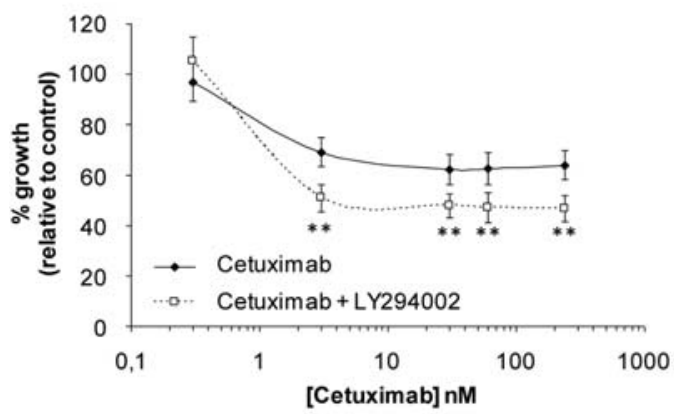

B

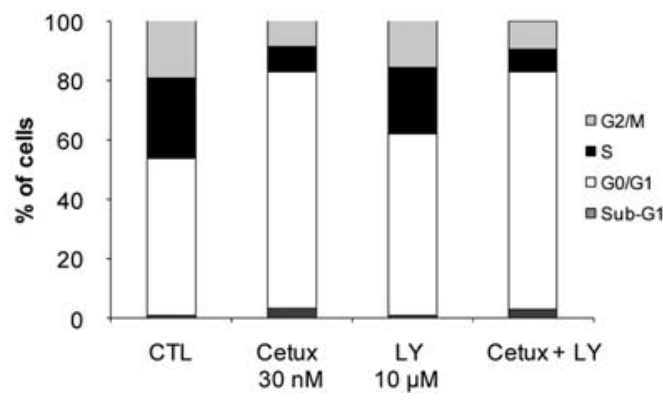

CAL33
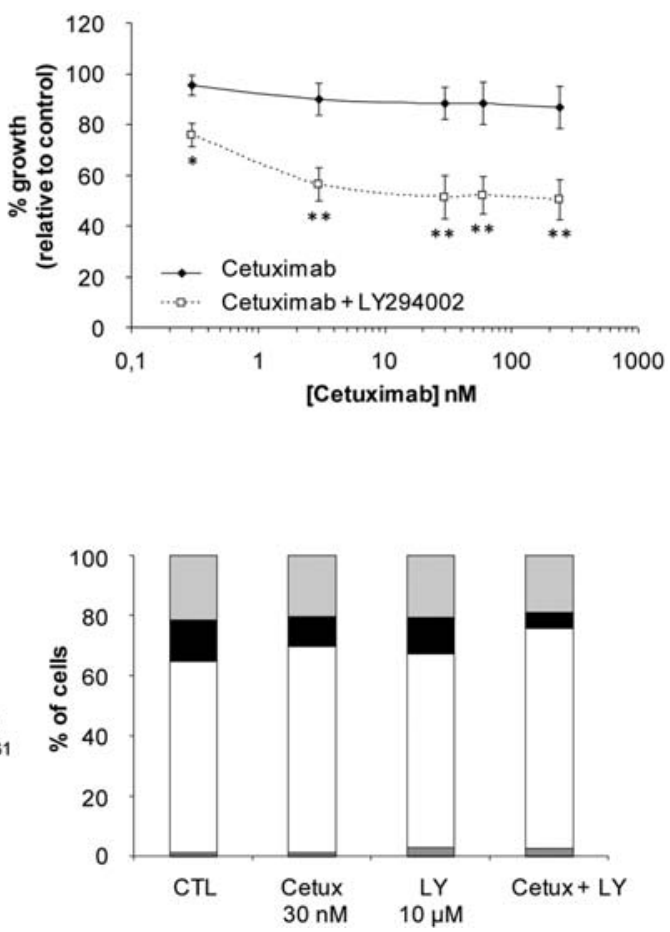

Figure 5. Effects of the combination of cetuximab and LY294002 on cell proliferation (A) and cell cycle distribution (B) in A431 and CAL33 cell lines. Cells were incubated with increasing concentrations of cetuximab with or without $10 \mu \mathrm{M} \mathrm{LY} 294002$ for $72 \mathrm{~h}$. (A), Cell proliferation was measured by MTS assay and shown as a percentage of the optical density value of control cells (untreated) for each concentration tested. Data are representative and correspond to the mean of three independent experiments $(\mathrm{n}=3)$ with standard deviation (SD). Asterisk indicates statistical significance $\left({ }^{*} \mathrm{p}<0.01,{ }^{* *} \mathrm{p}<0.001\right.$ compared to each dose). (B), Effect of cetuximab $(30 \mathrm{nM})$ alone or combined with LY294002 $(10 \mu \mathrm{M})$ for $72 \mathrm{~h}$ on cell cycle distribution by flow cytometric analysis. Cell distribution was analyzed by WinMDI software. Data are representative and correspond to the mean of three independent experiments $(n=3)$.

shift of the cytometric peak at $5 \mathrm{~min}$ (data not shown) and 30 min (Fig. 4A), indicating an increase in EGFR on cell surface membrane in relation to the increase of EGFR expression observed by Western blot analysis (Fig. 3A). In A431 untreated cells, EGFR was localized in a predominant plasma membrane staining, whereas a weak shift in cellular distribution of EGFR was detected upon EGF incubation (30 min and $6 \mathrm{~h}$ ) with minor punctuated intracellular staining (Fig. 4A). In addition, cetuximab also induces slight EGFR internalization/localization, which is maximal at $6 \mathrm{~h}$ with cell-to-cell localization. In CAL33 cells, EGF induced a strong leftward shift of the EGFR peak in a time-dependent manner (Fig. 4B), according to the results observed by Western blot analysis (Fig. 3B). In CAL33 untreated cells, EGFR presented diffuse plasma membrane staining, whereas a strong shift in cellular distribution of EGFR was detected upon 30 min of EGF incubation with punctuated intracellular staining, corresponding to EGFR internalization (Fig. 4B). At 6 and $24 \mathrm{~h}$, we observed a disappearance of the punctuated intracellular staining in relation to the strong decrease in total EGFR expression observed by Western blot analysis, corresponding to EGFR degradation (Fig. 3B). In CAL33, cetuximab induced only a slight shift of the cytometric peak (compared to EGF stimulation) in relation to the constant total EGFR expression visualized in Western blot analysis (Fig. 3B). These results were in agreement with the EGFR cellular distribution and cetuximab induced no modification in cellular EGFR distribution/localization in microscopy (Fig. 4B). These results showed that cetuximab did not induce the EGFR internalization/degradation in cetuximab-resistant cell line, in contrast to EGF treatment. This phenomenon could play a role in the absence of modification in the AKT pathway after cetuximab treatment in these cells. Then we analyzed the kinetic relation between EGFR and AKT phosphorylation in both cell lines (Fig. 3). EGF stimulation activated the AKT pathway after 5 min until $8 \mathrm{~h}$ in relation to the EGFR phosphorylation in A431 cells (Fig. 3A). Cetuximab inhibited AKT phosphorylation in relation to the inhibition of EGFR phosphorylation observed in the same time. In cetuximab-resistant CAL33 cells, no effect was observed on the kinetic of AKT activation despite the EGFR phosphorylation induced by EGF and cetuximab treatment (Fig. 3B).

Taken together, cetuximab inhibited AKT phosphorylation in cetuximab-sensitive cells but not in cetuximab-resistant cells. These data suggest that the persistence of AKT phosphorylation could play an important role in cetuximab-resistant cells.

Inhibition of PI3K/AKT pathway restores cetuximab sensitivity in cetuximab-resistant cell line. The possible mechanism of persistence of AKT activation could be alterations in PI3K/ AKT pathway. In order to investigate this mechanism, we sequenced the PIK3CA gene on exons 1, 2, 9, and 20, which is known to be mutated in cancer cells. We have shown that 
CAL33 cells present a mutation on exon 20 (c.3140A>G; p.H1047R). Depletion of the tumor suppressor PTEN can also increase growth factor-independent activity of the PI3K/AKT pathway. None of the cell lines harbored loss of $P T E N$. Therefore, we hypothesized that the inhibition of the PI3K pathway could restore the sensitivity of resistant cells to cetuximab and used LY294002, a synthetic PI3K inhibitor. Firstly, we confirmed that LY294002 inhibited specifically the AKT phosphorylation in CAL33 cell line (data not shown). We performed a cell growth assay and analyzed the cell cycle after cetuximab and LY294002 combination treatment (Fig. 5). Cells were treated with increasing doses of cetuximab with or without $10 \mu \mathrm{M}$ LY294002 for $72 \mathrm{~h}$. In A431 cells, we found $42 \%$ maximal growth inhibition in response to cetuximab treatment and $57 \%$ maximal growth inhibition in response to the cetuximab and LY294002 combination as early as $30 \mathrm{nM}$ (Fig. 5A). Interestingly, whereas we observed a weak effect of cetuximab on cell growth (11.6\% inhibition) in CAL33 cells, the addition of LY294002 to cetuximab induced a significant growth inhibition ( $49 \%$ inhibition, $\mathrm{p}<0.001$ ). This combination of treatment in CAL33 cells induced a comparable sensitivity to A431 cells. Cell cycle results confirmed that the effect of the LY294002-cetuximab combination on A431 cells was minor (Fig. 5B). In contrast, the strong growth inhibition observed in CAL33 cells is confirmed by a relevant decrease in $\mathrm{S}$ phase after cetuximab and LY294002 combination (5.5\% vs. $13.8 \%$, combination vs. cetuximab).

These results show that the inhibition of AKT phosphorylation by a PI3K inhibitor restores sensitivity to cetuximab in cell line mutated for PIK3CA and suggests that persistent AKT activation contributes to cetuximab resistance.

\section{Discussion}

Our study was conducted to elucidate the importance of EGFR signaling pathways in resistant HNSCC cells, which could lead to the optimization of EGFR-directed therapy. We focused our project on an HNSCC cell line (CAL33), described by several authors, which presents high EGFR expression and a wild-type EGFR, KRAS and BRAF status $(23,26,27)$. This is representative of the clinical situation in which EGFR and KRAS mutations seem to be rare events in HNSCC, compared to NSCLC. This is all the more interesting given that some cancers with wild-type EGFR status can also derive significant clinical benefit from anti-EGFR agents and develop resistance to anti-EGFR agents. Moreover, our study describes the presence of a PIK3CA activating mutation which encodes for the $\mathrm{p} 110 \alpha$ catalytic subunit of PI3K. Mutation of PIK3CA occurs in $8-11 \%$ in HNSCC $(28,29)$ and has been shown to activate the AKT signaling pathway (30). Whereas in mCRC mutations in the PI3K catalytic subunit have been reported to correlate with EGFR mAbs clinical resistance, scarce data on HNSCC are available (31-33).

We have shown that treatment of CAL33 cell line (as described in SQ20B) with different anti-EGFR agents induces differential antiproliferative effects. In these cells, cetuximab induces a weak antiproliferative effect and no modification of the cell cycle whereas gefitinib induces a high antiproliferative effect in relation to cell cycle modifications
$\left(\mathrm{G}_{0} / \mathrm{G}_{1}\right.$ arrest). Similar weak effects on cell cycle distribution after cetuximab treatment on potential resistant cell lines were previously reported in NSCLC (34) or HNSCC cells $(35,36)$. Interestingly, these data indicate that HNSCC cell lines present resistance to cetuximab and sensitivity to gefitinib independently to their EGFR expression. Indeed, there are controversial data on this relationship between EGFR expression and antiproliferative effect of anti-EGFR agents $(34,35)$. In agreement with our results, some authors have demonstrated that EGFR expression alone is not the only determinant influencing the antiproliferative activity of cetuximab or gefitinib treatments $(37,38)$. A number of other factors may determine the sensitivity/resistance of cells to EGFR inhibitors. We have hypothesized that EGFR downstream signaling pathways (ERK and AKT) and EGFR internalization/degradation could be some of these factors.

We investigated the EGFR signaling pathways after antiEGFR treatments in cetuximab-resistant cell line compared to cetuximab-sensitive cell line. Surprisingly, we found that cetuximab induces the EGFR phosphorylation at sites Y1068 and Y1173, respectively, implicated as a MAP kinase activation $(34,39)$ and the major phosphorylation site in resistant cell lines (40). These results are consistent with previous data showing that cetuximab is able to induce EGFR activation in NSCLC $(19,34)$ and $\operatorname{HNSCC}(40)$. EGFR phosphorylation is well described by authors but the underlying mechanisms remain unknown. Despite EGFR activation, we found a decrease in ERK phosphorylation and persistence of the AKT phosphorylation in cetuximab-resistant cells whereas sensitivity to cetuximab correlated with efficient blocking of ERK and AKT pathways in A431 cells. It has already been shown that resistance to cetuximab or gefitinib implicates a persistent activation of ERK and AKT pathways in breast cancers, NSCLC and HNSCC $(24,35,41)$. Unusually, this phenomenon occurs after cetuximab treatment in a cell line presenting a mutated PIK3CA in our study. However, we have shown that gefitinib is able to decrease the AKT phosphorylation despite the presence of PIK3CA mutation, in agreement with the literature (42). This persistent activation of signaling pathway in resistant cells could explain the limited efficacy of cetuximab and the minor effect on cell cycle progression after cetuximab exposure (35).

To understand the increase in EGFR phosphorylation after cetuximab treatment in resistant cell line, we have compared the changes in EGFR phosphorylation induced by cetuximab and EGF. As some relationships have been established between EGFR internalization processes and EGFR kinase activity after cetuximab treatment $(43,44)$ we hypothesized that resistance induced by cetuximab could relate to EGFR internalization/degradation and EGFR phosphorylation. Here cetuximab treatment did not induce EGFR internalization/ degradation in resistant cells, which correlates with the absence of phosphorylation at site Y1045 described as essential for the EGFR degradation $(45,46)$. In contrast, EGF induces EGFR internalization followed by strong EGFR degradation. In comparison, cetuximab and EGF induce weak EGFR internalization in sensitive cells, followed by weak EGFR degradation. The internalization process is relatively slow in sensitive cell lines whereas this process occurs predominantly at $6 \mathrm{~h}$ in resistant cells. These data are 
probably in relation with EGFR expression. Indeed, it has been shown that EGFR turnover ranges between 6-10 $\mathrm{h}$ in cells with low or moderate EGFR expression, whereas $t_{1 / 2}$ could be $24 \mathrm{~h}$ or longer in cells with EGFR overexpression (47). However, cetuximab did not induce EGFR internalization/degradation in resistant cells independently of EGFR expression. In consequence, we suggest that the absence of EGFR internalization/degradation plays a role in cetuximab resistance. Wheeler et al showed that EGFR internalization was impaired in acquired resistant cetuximab clones and may be responsible for cetuximab resistance (48). EGFR internalization could have both 'positive' and 'negative' effects on the signaling pathway. The internalization/degradation of activated EGFR decreases EGFR numbers on the cell surface and so induces a down-regulation of the EGFR signaling pathway, whereas it has been previously described that the EGF/EGFR complex remains active in endosomes and activates the signaling pathways after internalization $(19,22,47)$. However, it is uncertain whether signals from internalized EGFR could be qualitatively different from those induced at the cell surface (49). All these results have shown that the mechanisms of EGFR internalization/degradation remain uncertain. Our results suggest that cetuximab prevents EGFR turnover and degradation compared to EGF stimulation in resistant cells.

The analysis of the consequences on EGFR phosphorylation in resistant cells after cetuximab treatment has shown that EGFR phosphorylation (Y1173, Y1068) is accompanied by a persistence of AKT activation. In contrast, EGF and cetuximab produce a strong and prolonged modification of EGFR and AKT phosphorylation in sensitive cells. The absence of AKT phosphorylation after EGF treatment on resistant cell line can be explained by EGFR internalization/ degradation. Indeed, it has been demonstrated that signaling $\mathrm{PI} 3 \mathrm{~K} / \mathrm{AKT}$ pathway is restricted to the cell surface and therefore is not activated by internalized EGFR in endosomes $(50,51)$. These results suggest that inhibition of EGFR turnover induced by cetuximab is unlikely to be responsible for the non-modification of AKT phosphorylation.

We then examined the role of PIK3CA mutation in resistance to cetuximab and found that the resistant cell line is mutated on PI3K/AKT pathway. There is no relation between PIK3CA status and EGFR internalization/degradation because EGFR was internalized/degraded after EGF but not after cetuximab. In contrast, cetuximab and EGF which act in the EGFR extracellular domain are inefficient on AKT phosphorylation in these cells with PIK3CA activated mutation. However, gefitinib which acts in the EGFR tyrosine kinase domain is efficient in these cells. As recently shown, tumor cells can lose their dependence on growth factors by mutation-driven constitutive activation of signaling pathways downstream of growth factor receptors, specifically the PI3K and Ras/MAPK pathways (52). Our findings imply that cancer cell lines acquiring mutations that result in constitutive activation of the PI3K pathway have a diminished dependence on canonical EGFR ligand-induced signaling for their growth and are therefore more resistant to cetuximab treatment than to gefitinib treatment. Similar results were obtained in colorectal cancers (53). Therefore, the persistence of AKT activation in PIK3CA mutated cells is probably the most important factor in cetuximab resistance. We chose LY294002 because it inhibits preferentially in vitro the mutated PIK3CA cells as compared with wild-type PI3K (52). These results confirmed that this cell line could keep sensitivity to a specific PI3K inhibitor despite PIK3CA mutation. The combination of LY294002 with cetuximab restores cell sensitivity in the resistant cell line. Similar effects were observed in cetuximab-resistant NSCLC with PTEN instability (54). Moreover, the blockage of the AKT pathway by LY294002 has been shown to reduce tumor progression (55).

All these results have shown that absence of EGFR internalization/degradation and persistent AKT activation are partly responsible for cetuximab resistance in CAL33 cells. Therefore, targeting EGFR by another mechanism may retain effectiveness for cells manifesting cetuximab resistance. These results are very encouraging and confirm the interest of therapeutic combinations that are able to increase resistance to anti-EGFR agents. Development of therapies that affect only mutant forms of PIK3CA provides an additional way to increase specificity and limit the toxicity of such inhibitors (56). Together, our data suggest that treatment of HNSCC cell lines mutated for PI3K pathway with combination of cetuximab and a specific PI3K inhibitor is a good therapeutic option.

\section{Acknowledgements}

We would like to thank Dr Jean-Louis Fischel and Professor Eric Deustch for providing the cell lines and Dr Laurence Goossens and Dr Antonio Garofalo for providing the gefitinib. We would like to thank Merck for providing cetuximab. We gratefully acknowledge support from Dr Samuel Meignan for the critical review of the manuscript, Séverine Marchant for submission and Professor Pierre Formstecher, Director of JPARC. We would also like to thank Agence National de la Recherche Technique (ANRT), Centre Oscar Lambret, Institut pour la Recherche sur le Cancer de Lille (IRCL) for the PhD fellowship to M.R., and Service Commun d'Imagerie Cellulaire de l'IMPRT (IFR114) for access to the fluorescence microscope.

\section{References}

1. Mendelsohn J and Baselga J: The EGF receptor family as targets for cancer therapy. Oncogene 19: 6550-6565, 2000.

2. Kalyankrishna S and Grandis JR: Epidermal growth factor receptor biology in head and neck cancer. J Clin Oncol 24: 2666-2672, 2006.

3. Ciardiello F and Tortora G: Epidermal growth factor receptor (EGFR) as a target in cancer therapy: understanding the role of receptor expression and other molecular determinants that could influence the response to anti-EGFR drugs. Eur J Cancer 39: 1348-1354, 2003

4. Yarden Y and Sliwkowski MX: Untangling the ErbB signalling network. Nat Rev Mol Cell Biol 2: 127-137, 2001.

5. Rebucci M: Signaling and tumoral develoment. Oncologie 11: 117-122, 2009

6. Harari PM: Epidermal growth factor receptor inhibition strategies in oncology. Endocr Relat Cancer 11: 689-708, 2004.

7. Imai $\mathrm{K}$ and Takaoka $\mathrm{A}$ : Comparing antibody and smallmolecule therapies for cancer. Nat Rev Cancer 6: 714-727, 2006.

8. Baselga J: The EGFR as a target for anticancer therapy - focus on cetuximab. Eur J Cancer 37 (Suppl 4): S16-S22, 2001. 
9. Vincenzi B, Schiavon G, Silletta M, Santini D and Tonini G: The biological properties of cetuximab. Crit Rev Oncol Hematol 68: 93-106, 2008.

10. Arnoletti JP, Buchsbaum DJ, Huang ZQ, Hawkins AE, Khazaeli MB, Kraus MH and Vickers SM: Mechanisms of resistance to Erbitux (anti-epidermal growth factor receptor) combination therapy in pancreatic adenocarcinoma cells. J Gastrointest Surg 8: 960-969, 2004.

11. Bonner JA, Harari PM, Giralt J, et al: Radiotherapy plus cetuximab for squamous-cell carcinoma of the head and neck. N Engl J Med 354: 567-578, 2006.

12. Cunningham D, Humblet Y, Siena S, et al: Cetuximab monotherapy and cetuximab plus irinotecan in irinotecan-refractory metastatic colorectal cancer. N Engl J Med 351: 337-345, 2004.

13. Cohen EE, Rosen F, Stadler WM, Recant W, Stenson K, Huo D and Vokes EE: Phase II trial of ZD1839 in recurrent or metastatic squamous cell carcinoma of the head and neck. J Clin Oncol 21 : 1980-1987, 2003.

14. Vermorken JB, Trigo J, Hitt R, et al: Open-label, uncontrolled, multicenter phase II study to evaluate the efficacy and toxicity of cetuximab as a single agent in patients with recurrent and/or metastatic squamous cell carcinoma of the head and neck who failed to respond to platinum-based therapy. J Clin Oncol 25: 2171-2177, 2007.

15. Chen LF, Cohen EE and Grandis JR: New strategies in head and neck cancer: understanding resistance to epidermal growth factor receptor inhibitors. Clin Cancer Res 16: 2489-2495, 2010.

16. Ishikawa N, Daigo Y, Takano A, et al: Increases of amphiregulin and transforming growth factor-alpha in serum as predictors of poor response to gefitinib among patients with advanced nonsmall cell lung cancers. Cancer Res 65: 9176-9184, 2005.

17. She QB, Solit D, Basso A and Moasser MM: Resistance to gefitinib in PTEN-null HER-overexpressing tumor cells can be overcome through restoration of PTEN function or pharmacologic modulation of constitutive phosphatidylinositol 3'-kinase/Akt pathway signaling. Clin Cancer Res 9: 4340-4346, 2003.

18. Kobayashi S, Boggon TJ, Dayaram T, et al: EGFR mutation and resistance of non-small-cell lung cancer to gefitinib. N Engl J Med 352: 786-792, 2005

19. Yoshida T, Okamoto I, Okabe T, et al: Matuzumab and cetuximab activate the epidermal growth factor receptor but fail to trigger downstream signaling by Akt or Erk. Int J Cancer 122: 1530-1538, 2008

20. Vieira AV, Lamaze C and Schmid SL: Control of EGF receptor signaling by clathrin-mediated endocytosis. Science 274: 2086-2089, 1996

21. Sorkin A and Von ZM: Signal transduction and endocytosis: close encounters of many kinds. Nat Rev Mol Cell Biol 3: 600-614, 2002.

22. Wang Y, Pennock S, Chen X and Wang Z: Endosomal signaling of epidermal growth factor receptor stimulates signal transduction pathways leading to cell survival. Mol Cell Biol 22: 7279-7290, 2002.

23. Gioanni J, Fischel JL, Lambert JC, et al: Two new human tumor cell lines derived from squamous cell carcinomas of the tongue: establishment, characterization and response to cytotoxic treatment. Eur J Cancer Clin Oncol 24: 1445-1455, 1988.

24. Janmaat ML, Kruyt FA, Rodriguez JA and Giaccone G: Response to epidermal growth factor receptor inhibitors in nonsmall cell lung cancer cells: limited antiproliferative effects and absence of apoptosis associated with persistent activity of extracellular signal-regulated kinase or Akt kinase pathways. Clin Cancer Res 9: 2316-2326, 2003.

25. Meira DD, Nobrega I, De Almeida V, et al: Different antiproliferative effects of matuzumab and cetuximab in A431 cells are associated with persistent activity of the MAPK pathway. Eur J Cancer 45: 1265-1273, 2009.

26. Bozec A, Lassalle S, Gugenheim J, Fischel JL, Formento P, Hofman P and Milano G: Enhanced tumour antiangiogenic effects when combining gefitinib with the antivascular agent ZD6126. Br J Cancer 95: 722-728, 2006.

27. Magne N, Fischel JL, Dubreuil A, Formento P, Marcie S, Lagrange JL and Milano G: Sequence-dependent effects of ZD1839 ('Iressa') in combination with cytotoxic treatment in human head and neck cancer. Br J Cancer 86: 819-827, 2002.

28. Qiu W, Schonleben F, Li X, et al: PIK3CA mutations in head and neck squamous cell carcinoma. Clin Cancer Res 12: 1441-1446, 2006
29. Ligresti G, Militello L, Steelman LS, et al: PIK3CA mutations in human solid tumors: role in sensitivity to various therapeutic approaches. Cell Cycle 8: 1352-1358, 2009.

30. Pedrero JM, Carracedo DG, Pinto CM, Zapatero AH, Rodrigo JP, Nieto CS and Gonzalez MV: Frequent genetic and biochemical alterations of the PI 3-K/AKT/PTEN pathway in head and neck squamous cell carcinoma. Int J Cancer 114: 242-248, 2005.

31. Krystal GW, Sulanke G and Litz J: Inhibition of phosphatidylinositol 3-kinase-Akt signaling blocks growth, promotes apoptosis, and enhances sensitivity of small cell lung cancer cells to chemotherapy. Mol Cancer Ther 1: 913-922, 2002.

32. Sartore-Bianchi A, Martini M, Molinari F, et al: PIK3CA mutations in colorectal cancer are associated with clinical resistance to EGFR-targeted monoclonal antibodies. Cancer Res 69: 1851-1857, 2009.

33. MacKeigan JP, Taxman DJ, Hunter D, Earp HS III, Graves LM and Ting JP: Inactivation of the antiapoptotic phosphatidylinositol 3-kinase-Akt pathway by the combined treatment of taxol and mitogen-activated protein kinase kinase inhibition. Clin Cancer Res 8: 2091-2099, 2002.

34. Raben D, Helfrich B, Chan DC, et al: The effects of cetuximab alone and in combination with radiation and/or chemotherapy in lung cancer. Clin Cancer Res 11: 795-805, 2005

35. Yamatodani T, Ekblad L, Kjellen E, Johnsson A, Mineta H and Wennerberg J: Epidermal growth factor receptor status and persistent activation of Akt and p44/42 MAPK pathways correlate with the effect of cetuximab in head and neck and colon cancer cell lines. J Cancer Res Clin Oncol 135: 395-402, 2009.

36. Huang SM, Bock JM and Harari PM: Epidermal growth factor receptor blockade with $\mathrm{C} 225$ modulates proliferation, apoptosis, and radiosensitivity in squamous cell carcinomas of the head and neck. Cancer Res 59: 1935-1940, 1999.

37. Huang S, Armstrong EA, Benavente S, Chinnaiyan P and Harari PM: Dual-agent molecular targeting of the epidermal growth factor receptor (EGFR): combining anti-EGFR antibody with tyrosine kinase inhibitor. Cancer Res 64: 5355-5362, 2004.

38. Moasser MM, Basso A, Averbuch SD and Rosen N: The tyrosine kinase inhibitor ZD1839 ('Iressa') inhibits HER2-driven signaling and suppresses the growth of HER2-overexpressing tumor cells. Cancer Res 61: 7184-7188, 2001.

39. Nyati MK, Morgan MA, Feng FY and Lawrence TS: Integration of EGFR inhibitors with radiochemotherapy. Nat Rev Cancer 6: 876-885, 2006.

40. Mandic R, Rodgarkia-Dara CJ, Zhu L, et al: Treatment of HNSCC cell lines with the EGFR-specific inhibitor cetuximab (Erbitux) results in paradox phosphorylation of tyrosine 1173 in the receptor. FEBS Lett 580: 4793-4800, 2006.

41. Normanno N, De Luca A, Maiello MR, et al: The MEK/MAPK pathway is involved in the resistance of breast cancer cells to the EGFR tyrosine kinase inhibitor gefitinib. J Cell Physiol 207: 420-427, 2006

42. Magne N, Fischel JL, Tiffon C, et al: Molecular mechanisms underlying the interaction between ZD1839 ('Iressa') and cisplatin/5-fluorouracil. Br J Cancer 89: 585-592, 2003.

43. Sunada H, Magun BE, Mendelsohn J and MacLeod CL: Monoclonal antibody against epidermal growth factor receptor is internalized without stimulating receptor phosphorylation. Proc Natl Acad Sci USA 83: 3825-3829, 1986.

44. Jaramillo ML, Leon Z, Grothe S, Paul-Roc B, Abulrob A and O'Connor MM: Effect of the anti-receptor ligand-blocking 225 monoclonal antibody on EGF receptor endocytosis and sorting. Exp Cell Res 312: 2778-2790, 2006.

45. Song JY, Lee SW, Hong JP, Chang SE, Choe H and Choi J: Epidermal growth factor competes with EGF receptor inhibitors to induce cell death in EGFR-overexpressing tumor cells. Cancer Lett 283: 135-142, 2009.

46. Han W, Zhang T, Yu H, Foulke JG and Tang CK: Hypophosphorylation of residue Y1045 leads to defective downregulation of EGFRvIII. Cancer Biol Ther 5: 1361-1368, 2006.

47. Sorkin A and Goh LK: Endocytosis and intracellular trafficking of ErbBs. Exp Cell Res 315: 683-696, 2009.

48. Wheeler DL, Huang S, Kruser TJ, et al: Mechanisms of acquired resistance to cetuximab: role of HER (ErbB) family members. Oncogene 27: 3944-3956, 2008.

49. Burke P, Schooler K and Wiley HS: Regulation of epidermal growth factor receptor signaling by endocytosis and intracellular trafficking. Mol Biol Cell 12: 1897-1910, 2001. 
50. Haugh JM, Schooler K, Wells A, Wiley HS and Lauffenburger DA: Effect of epidermal growth factor receptor internalization on regulation of the phospholipase C-gamma1 signaling pathway. J Biol Chem 274: 8958-8965, 1999.

51. Haugh JM, Huang AC, Wiley HS, Wells A and Lauffenburger DA: Internalized epidermal growth factor receptors participate in the activation of $\mathrm{p} 21$ (ras) in fibroblasts. J Biol Chem 274: 34350-34360, 1999.

52. Samuels Y, Diaz LA Jr, Schmidt-Kittler O, et al: Mutant PIK3CA promotes cell growth and invasion of human cancer cells. Cancer Cell 7: 561-573, 2005.

53. Jhawer M, Goel S, Wilson AJ, et al: PIK3CA mutation/PTEN expression status predicts response of colon cancer cells to the epidermal growth factor receptor inhibitor cetuximab. Cancer Res 68: 1953-1961, 2008.
54. Kim SM, Kim JS, Kim JH, et al: Acquired resistance to cetuximab is mediated by increased PTEN instability and leads cross-resistance to gefitinib in HCC827 NSCLC cells. Cancer Lett 296: 150-159, 2010

55. Hu L, Hofmann J, Lu Y, Mills GB and Jaffe RB: Inhibition of phosphatidylinositol 3'-kinase increases efficacy of paclitaxel in in vitro and in vivo ovarian cancer models. Cancer Res 62: 1087-1092, 2002.

56. Samuels Y and Velculescu VE: Oncogenic mutations of PIK3CA in human cancers. Cell Cycle 3: 1221-1224, 2004. 